\title{
Surface modification of Ti-4AI-2V alloy by nitrogen implantation
}

\author{
Z. G. WANG, X. T. ZU*, X. XIANG \\ Department of Applied Physics, University of Electronic Science and Technology of China, \\ Chengdu 610054, People's Republic of China \\ E-mail: xtzu@uestc.edu.cn
}

S. ZHU, L. M. WANG

Department of Nuclear Engineering and Radiological Sciences, University of Michigan, MI, Ann Arbor 48109-2014, USA

Published online: 12 April 2006

Ti-4Al-2V is a new type of alpha titanium alloy that suitable for the application in high-temperature and high-pressure water/steam environment. Ti-4Al-2V can be used in marine engineering, nuclear power industry. In this paper the surface characterization of the Ti-4AI-2V implanted with $75 \mathrm{keV}$ nitrogen with fluences of $3 \times 10^{17}$ and $8 \times 10^{17} \mathrm{~N}^{+} / \mathrm{cm}^{2}$ is investigated by glancing-incidence XRD, XPS and microhardness. The results show that new phase TiN are formed after $N$ implantation in the surface region. The nitrogen implantation increases the surface hardness up to 340 and $260 \%$ for fluence of $8 \times 10^{17}$ and $3 \times 10^{17} \mathrm{~N}^{+} / \mathrm{cm}^{2}$, respectively. The enhancement of hardness is related to the formation of TiN and irradiation induced hardness. (C) 2006 Springer Science + Business Media, Inc.

\section{Introduction}

Ti-4Al-2V is a new type of alpha titanium alloy that suitable for the application in high-temperature and highpressure water/steam environment. It has moderate tensile strength, good weldability, anti-corrosion performance, and fine property under low temperatures. It could be used in marine engineering, nuclear power industry in the future [1]. As it is a new type of titanium alloy, there are little reports about it. We have investigated the oxidation behavior of this titanium alloy in high-temperature and highpressure alkaline water steam [2], the analyses of XRD pattern and XPS and in situ AES show that the oxide scales are composed of brookite- $\mathrm{TiO}_{2}, \mathrm{Al}_{2} \mathrm{TiO}_{5}\left(\mathrm{Al}_{2} \mathrm{O}_{3} \cdot \mathrm{TiO}_{2}\right)$, $\mathrm{Ti}_{3} \mathrm{O}_{5}$ and $\mathrm{Ti}_{2} \mathrm{O}_{3}$, and the oxidation resistance has been improved by pre-oxidation process. While this titanium alloy oxidized in high-temperature and high-pressure neutral water steam, a layer of anatase- $\mathrm{TiO}_{2}$ was formed [3], the $\mathrm{OH}^{-}$maybe play an important role on the formation of different type of $\mathrm{TiO}_{2}$.

Ion implantation has most of superior qualities as surface modification methods. It has several merits compared with other modification methods: low temperature treatment, hence without dimensional change of treated components; no interface discontinuity as in film de- position hence avoiding delamination; possibilities of new structures in non equilibrium and new metallurgical phases; and precisely control of ion fluence and depth distribution. Nitrogen ion implantation has been successfully used to improve the corrosion resistance, hardness and tribological properties [4-10]. So the $N$ implantation also can improve the surface properties of Ti-4Al-2V. In this work, $75 \mathrm{keV}$ nitrogen is implanted into Ti-4Al-2V, the surface characterization is investigated by glancingincidence XRD, XPS and microhardness.

\section{Experiment}

Ti-4Al-2V samples were cut from a rod to disc specimens with diameter of $8 \mathrm{~mm}$ and thickness of $2.0 \mathrm{~mm}$. These specimens were ground and finally polished with a colloidal silica polishing suspension. The specimens were subsequently cleaned in acetone, alcohol and deionized water in turn. Argon ion bombardment cleaning was carried out at a bias of $20 \mathrm{keV}$ in a vacuum for approximately 5 min for cleaning the sample surface before ion implantation. The $75 \mathrm{keV} \mathrm{N}^{+}$ion implantation was performed using the K280 accelerator with fluences of $3 \times$ $10^{17}$ and $8 \times 10^{17} \mathrm{~N}^{+} / \mathrm{cm}^{2}$. The beam current density was

*Author to whom all correspondence should be addressed. 


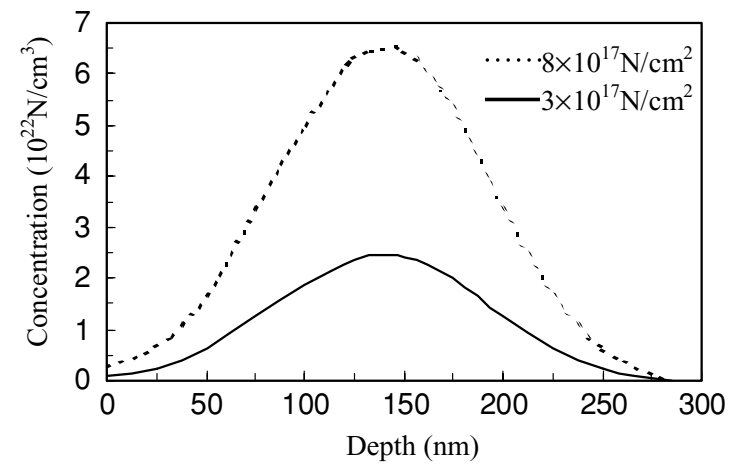

Figure 1 Depth distribution of nitrogen in Ti-4Al-2V after $75 \mathrm{~N}^{+}$implantation. The profile is simulated with TRIM96.

$16.3 \mu \mathrm{A} / \mathrm{cm}^{2}$. During $N$ implantation, the sample temperature was maintained below $200^{\circ} \mathrm{C}$ in order to avoid the oxidation of titanium. The base pressure in the vacuum chamber was $4.5 \times 10^{-6}$ Torr, and the working pressure was $1.2 \times 10^{-5}$ Torr. According to TRIM 96 [11] calculations, the longitudinal projected range of $1200 \AA$ with a lateral range of $420 \AA$. The final distribution of $N$ ion calculated with TRIM 96 is shown in Fig. 1. The distribution of implanted $\mathrm{N}^{+}$ions as a function of depth can be calculated as follows:

$$
C=N(\text { number/Angs. } \cdot \text { ion }) \times \text { fluence }\left(\text { ion } / \mathrm{cm}^{2}\right)
$$

where, $C$ is the implantation ion concentration, $N$ is the number calculated from TRIM code, the displacement energy $25 \mathrm{eV}$ was used for the secondary cascades calculation.

The structure of the implanted layers was investigated by glancing-incidence XRD (GXRD) with a Xray diffractometer type Philips X'Pert Pro MPD with a graphite monochromator, using $\mathrm{Cu} \mathrm{K} \alpha$ radiation and $1.2^{\circ}$ incident angel for the samples implanted with $3 \times 10^{17}$ and $8 \times 10^{17} \mathrm{~N}^{+} / \mathrm{cm}^{2}$.

The samples were also analyzed by XPS using a XSAM 800 Flexo electron spectrometer with monochromatic $\mathrm{Mg}$ $\mathrm{K}$-alpha $\mathrm{X}$-ray radiation. The instrument was standardized against the $\mathrm{C} 1 \mathrm{~s}$ spectral line at $285 \mathrm{eV}$, and the spectra were interpreted and deconvoluted using the KRATOA computer software package. Survey spectra in the range 0-1000 eV were recorded for each ion implanted sample, followed by higher resolution spectra over the N1s and Ti2p.

The microhardness was measured with an ultramicroharness tester DUH-202 from Shimadzu using a Vickers Indenter. Each Measurement was repeated 10 times in order to average out statistical fluctuation.

\section{Results and discussion}

\subsection{XRD investigation of the samples with and without $N$ implantation}

X-ray diffraction pattern and GIXRD patterns of the samples with and without $N$ implantation are shown in Fig. 2.

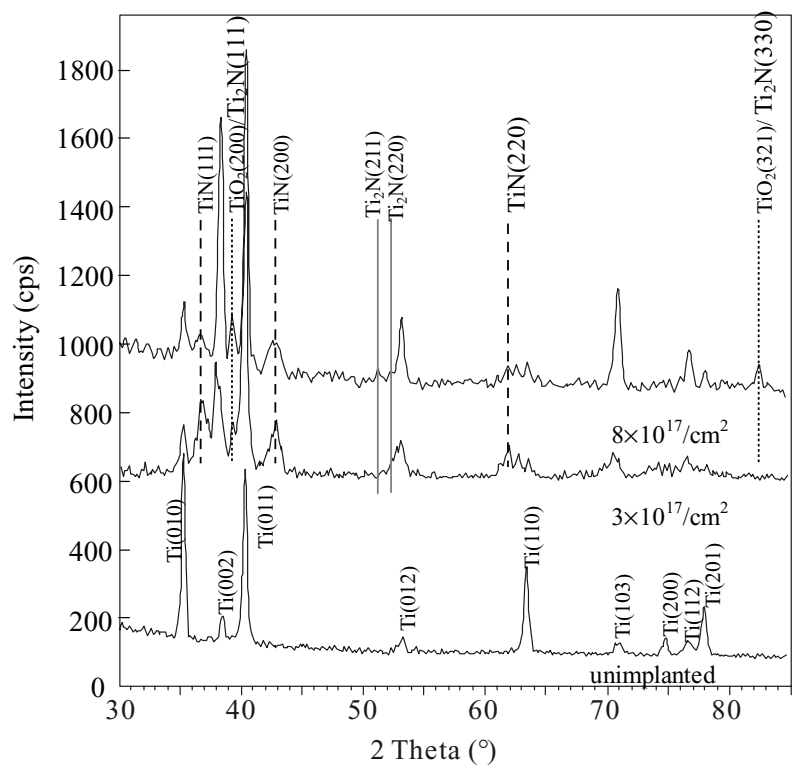

Figure 2 XRD diffraction patterns of $\mathrm{N}^{+}$implanted into Ti-4Al-2V showing new phase are formed after implantation.

It is evident for the sample without $N$ implantation that the peaks are all attributed to $\alpha$ phase titanium, and there is no $\beta$ phase diffraction peak in the alloy. This is consistent with previous reports [1]. GXRD reveals noticeable phase changes in the surface layer of implanted titanium. There are some new peaks appear at $2 \theta=36.65,39.26,42.76$, $51.06,61.80$ and $82.20^{\circ}$, which reveal that new phases are formed after $N$ implantation. The new phases are TiN, $\mathrm{Ti}_{2} \mathrm{~N}$ and rutile- $\mathrm{TiO}_{2}$ as indexed in Fig. 2. The $\mathrm{TiO}_{2}$ peaks are very small, suggesting a low volume fraction of this phase formed in this alloy. The formation of $\mathrm{TiO}_{2}$ is due to the low vacuum during $N$ implantation probably.

Because the TiN crystal has a NaCl-type structure, the lattice constants of the TiN crystal can be calculated according to the following Equation: $A=d\left(h^{2}+k^{2}+l^{2}\right)^{1 / 2}$, the $a$ of TiN formed by $N$ implanted into titanium calculated from $\mathrm{TiN}(111)$ is $4.24 \AA$, which is similar to the tabulated lattice constant $4.2417 \AA$ [12 ] indicating there's maybe little intrinsic stress generated after the new phase TiN formation. We know that nitrogen content and stress may influence the lattice constant, hence the non-shifted lattice constant maybe induced by the presence of substoichiometric TiN and intrinsic stress. Further investigations are needed to confirm whether intrinsic stress is generated after implantation.

\subsection{XPS analysis}

Fig. 3 shows the XPS surveys between binding energies of $0-1000 \mathrm{eV}$ for $75 \mathrm{keV} \mathrm{N}^{+}$implanted Ti-4Al-2V alloy surface. The dominant signals are $\mathrm{C}, \mathrm{O}, \mathrm{Ti}$ and $\mathrm{N}$. Comparing the XPS survey of the two samples implanted with different fluences, it is evident the $N$ signal increased with increasing fluence. This indicates that a larger fraction of nitride must be formed. The element $\mathrm{O}$ may be originated 


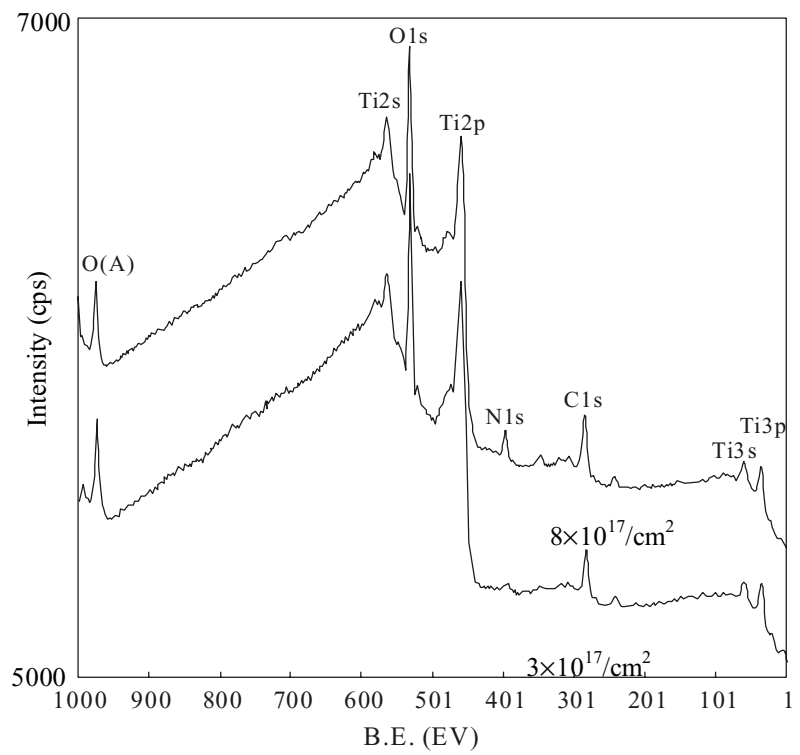

Figure 3 XPS survey energy spectra of $\mathrm{N}^{+}$implanted into Ti-4Al-2V with fluence of $3 \times 10^{17}$ and $8 \times 10^{17} \mathrm{~N}^{+} / \mathrm{cm}^{2}$.

from atmospheric contamination or $\mathrm{TiO}_{2}$ formation due to the lower vacuum during $N$ implantation. High-resolution XPS collections of the Ti $2 p$ binding energy regions have been made. Fig 4a shows the data deconvolution from $\mathrm{N}^{+}$implanted Ti-4Al-2V alloy surface for $3 \times 10^{17}$ and $8 \times 10^{17} \mathrm{~N}^{+} / \mathrm{cm}^{2}$, respectively. The photoelectron spectra of Ti $2 p_{3 / 2}$ of the sample implanted with a fluence of $3 \times 10^{17} \mathrm{~N}^{+} / \mathrm{cm}^{2}$ is curve fitted by four peaks at 458.81 , $457.29,455.08$ and 455.90 , which correspond with rutile$\mathrm{TiO}_{2}, \mathrm{Ti}_{2} \mathrm{O}_{3}$, $\mathrm{TiO}$ and $\mathrm{TiN}$ with an atomic percentage of
20 at.\%. And photoelectron spectra of $\mathrm{Ti} 2 \mathrm{p}_{3 / 2}$ of the sample implanted with a fluence of $8 \times 10^{17} \mathrm{~N}^{+} / \mathrm{cm}^{2}$ also can be fitted by four peaks corresponded with rutile- $\mathrm{TiO}_{2}$, $\mathrm{Ti}_{2} \mathrm{O}_{3}, \mathrm{TiO}$ and $\mathrm{TiN}$ with an atomic percentage of 47 at. $\%$. The photoelectron spectrum of N1s, as shown in Fig. 4b, was curve fitted, resulting in the binding energy values at $396.88 \mathrm{eV}$ for TiN with an atomic percentage of 69 at.\% and at $400.26 \mathrm{eV}$ for $\mathrm{C}-\mathrm{N}$ bond for the sample implanted with a fluence of $3 \times 10^{17} \mathrm{~N}^{+} / \mathrm{cm}^{2}$ and the atomic percentage of TiN increased to 79 at. $\%$ after $8 \times 10^{17} \mathrm{~N}^{+} / \mathrm{cm}^{2}$ implantation. It shows that more TiN formed after higher fluence of $N$ implantation.

The depth profiles were obtained by rastering a $5 \mathrm{keV}$ $\mathrm{Ar}^{+}$beam. The etching rate is estimated about $10 \AA / \mathrm{min}$. The vacuum was $1 \times 10^{-5} \mathrm{~Pa}$ during ion etching. Fig. 5 displays high-resolution Ti2p spectra of Ti-4Al-2V implanted with an ion dose of $3 \times 10^{17} \mathrm{~N} / \mathrm{cm}^{2}$ and $8 \times$ $10^{17} \mathrm{~N} / \mathrm{cm}^{2}$ that were recorded with the depth profile. It indicates that the Ti2p spectra comprises a combination of three XPS doubles, attributable to $\mathrm{Ti}^{4+}, \mathrm{Ti}^{3+}$ and $\mathrm{Ti}^{+}$ and corresponding to $\mathrm{TiO}_{2}, \mathrm{Ti}_{2} \mathrm{O}_{3}$, TiN. We can see that the relative ratio of $\mathrm{Ti}^{+}$was increased with increasing the depth. This result has similar trend as shown in Fig. 1.

\subsection{Microhardness}

The hardness as a function of indentation depth for $75 \mathrm{KeV}$ $\mathrm{N}^{+}$implanted Ti-4Al-2V with fluence of $3 \times 10^{17}$ and 8 $\times 10^{17} \mathrm{~N}^{+} / \mathrm{cm}^{2}$ was shown in Fig. 5 for a maximum load of $5 \mathrm{mN}$, normalized to the non-implanted sample $(2.9 \mathrm{GPa})$. The results showed that the hardness increase with increasing implanted fluences. The nitrogen implan-
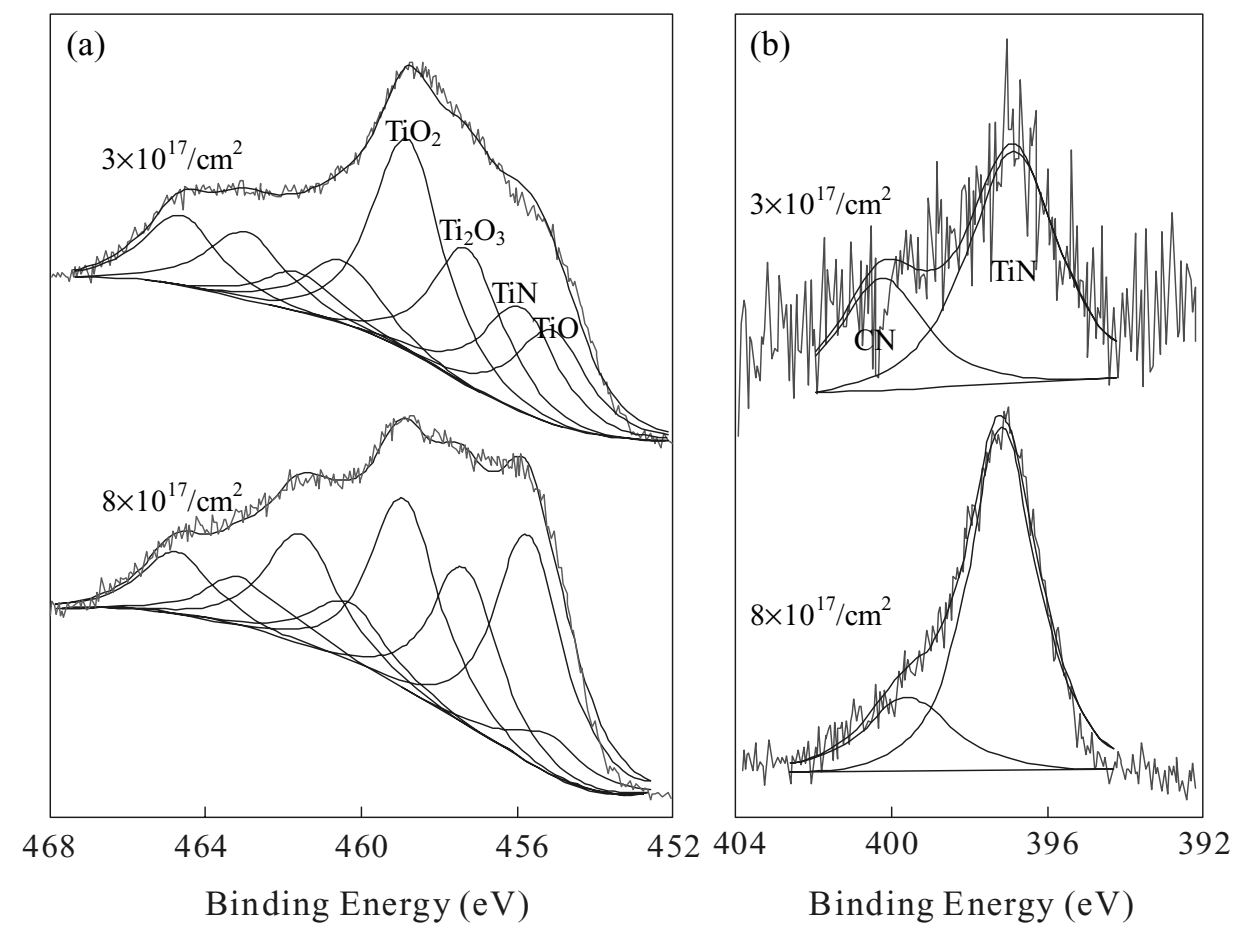

Figure 4 (a) Ti 2p and (b) $N$ 1s XPS energy spectrum of $\mathrm{N}^{+}$implanted into Ti-4Al-2V with fluence of $3 \times 10^{17}$ and $8 \times 10^{17} \mathrm{~N}^{+} / \mathrm{cm}^{2}$. 

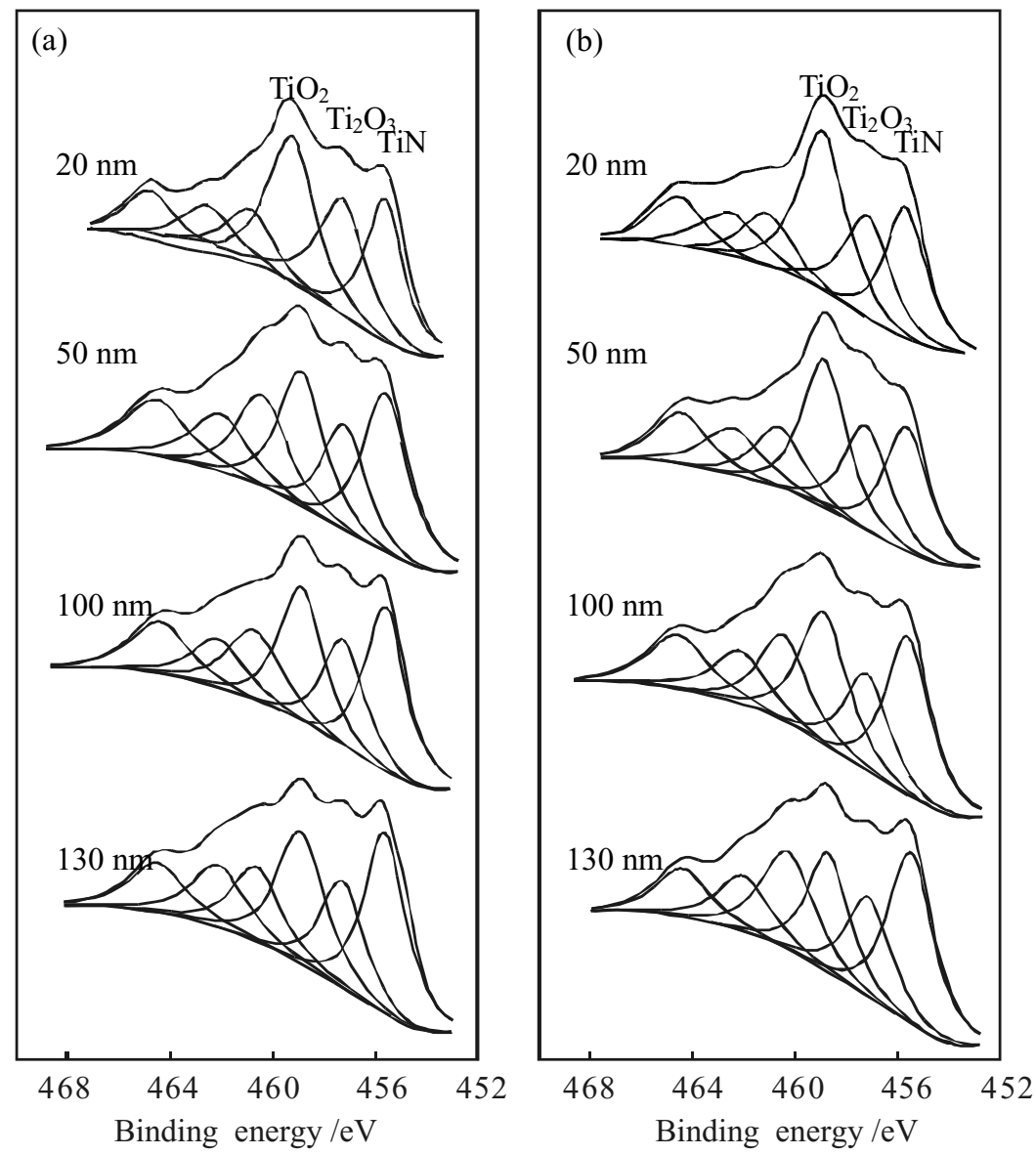

Figure 5 Depth profile of Ti 2p XPS energy spectrum of $\mathrm{N}^{+}$implanted into Ti-4Al-2V with fluence of (a) $3 \times 10^{17}$ and (b) $8 \times 10^{17} \mathrm{~N}^{+} / \mathrm{cm}^{2}$.

tation increases the surface hardness up to 340 and $260 \%$ for fluences of $8 \times 10^{17}$ and $3 \times 10^{17} \mathrm{~N}^{+} / \mathrm{cm}^{2}$, respectively. The hardness increases with the fluence, which was also observed by other authors [10,13-15]. The hardness test represents material characteristics from a region of three to six times the indentation depth of the probing tip, depending on the alloy. Comparing nitrogen depth profiles of Fig. 1 and relative depth functions of Fig. 6 it follows that the significant decrease of the micro hardness at an indentation depth exceeding 50-60 nm, while the nitrogen concentration maximum is at $130-150 \mathrm{~nm}$. Thus, a factor of 2-3 is appropriate for this alloy when comparing the depth scales of hardness and nitrogen concentration, respectively. This is consistent with the results of Ti6Al4V alloy [5].

The XRD and XPS analysis shows that $\mathrm{TiN}$ and $\mathrm{TiN}_{2}$ are formed after $N$ implantation. And the $\mathrm{TiN}$ and $\mathrm{Ti}_{2} \mathrm{~N}$ distributed as small precipitates in the titanium matrix [16]. It is well known that the element distribution, new phase formation and microstructure change of the modification layer has a close relationship with the surface properties of implanted alloy. The surface hardness of titanium also can be improved by irradiation [17-19]. The damage profile also been calculated by TRIM-96. The peak damage is $\sim 525$ displacement per atoms (dpa) and $\sim 200 \mathrm{dpa}$ at a depth of about $100 \mathrm{~nm}$ for the fluence of

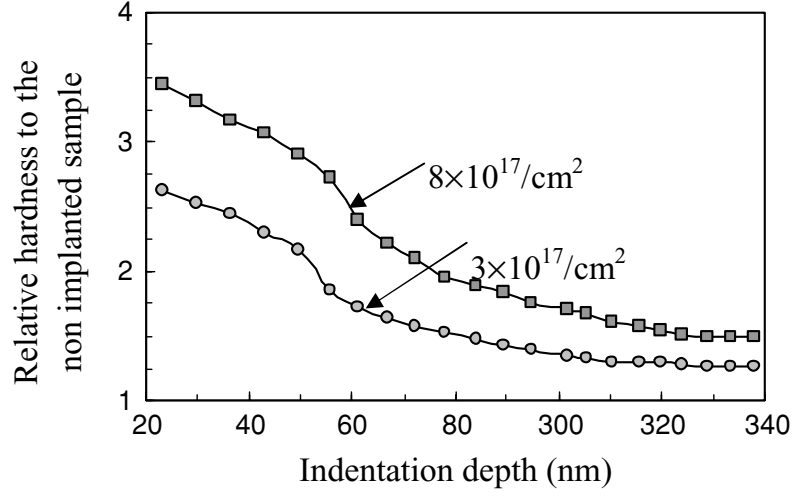

Figure 6 Hardness as a function of depth in the $75 \mathrm{KeV} \mathrm{N}^{+}$implanted Ti4Al2V with the fluence of $3 \times 10^{17}$ and $8 \times 10^{17} \mathrm{~N}^{+} / \mathrm{cm}^{2}$, normalized to the non-implanted sample. The maximum load was $5 \mathrm{mN}$.

$8 \times 10^{17}$ and $3 \times 10^{17} \mathrm{~N}^{+} / \mathrm{cm}^{2}$. The formation of new phase titanium nitride irradiation damage must contribute to the enhancement of hardness of Ti-4Al-2V.

\section{Conclusion}

The surface characterization of Ti-4Al-2V implanted with $75 \mathrm{keV}$ nitrogen with fluences of $3 \times 10^{17}$ and $8 \times 10^{17} \mathrm{~N}^{+} / \mathrm{cm}^{2}$ was studied by glancing-angle XRD 
and XPS. The results showed that new phase TiN are formed after $N$ implantation in the surface region. The hardness of a Ti-4Al-2V alloy was enhanced after nitrogen ion implantation. The nitrogen implantation increased the surface hardness up to 340 and $260 \%$ for fluence of 8 $\times 10^{17}$ and $3 \times 10^{17} \mathrm{~N}^{+} / \mathrm{cm}^{2}$, respectively.

\section{Acknowledgments}

This study was supported financially by the National Key Laboratory for Nuclear Fuel and Materials, Nuclear Power Institute of China and by the Program for New Century Excellent Talents in University (NCET-04-0899) and the Ph.D. Funding Support Program of Education Ministry of China (20050614013) and by the Sichuan Young Scientists Foundation (03ZQ026-059).

\section{References}

1. D. LI, Z. T. YU, W. S. TANG and J. DENG, J.Mater. Sci.Technol. 17 (2001) 77.

2. X. T. ZU, Z. G. WANG, X. D. FENG, Y. HUO, Y. L. LI and X. Q. HUANG, Surf. Coat. Technol. 140 (2001) 161.

3. Z. G. WANG, X. T. ZU, J. LIAN, X. Q. HUANG, L. WANG, Y. Z. LIU and L. M. WANG, J. Alloy. Comp. 384 (2004) 93.

4. X. T. ZU,Z. G. WANG, X. D. FENG, C. F. ZHANG, S. ZHU and Q. YU, ibid. 351 (2003) 114.

5. F. BERBERICH, W. MATZ, E. RICHTER, N. SCHELL, U. KRES SIG and W. MÖLLER, Surf. Coat. Technol. 128-129 (2000) 450.
6. F. BERBERICH, W. MATZ, U. KRESSIG, N. SCHELL and A. MÜ C K LICH, Nucl. Instr. Meth. B199 (2003) 54.

7. F. BERBERICH, W. MATZ, U. KRESSIG, E. RCHTER, N. SCHELL and W. MÖKKER, Appl. Surf. Sci. 179 (2001) 13.

8. J. M. WILLIAMS, L. RIESTER, R. PANDEY and A. W. EBERH AR D T, Surf. Coat. Tech. 88 (1996) 132.

9. Y. ITOH, A. ITOH, H. AZUMA and T. HIOKI, ibid. 111 (1999) 172.

10. M. UEDA, M. M. SILVA, C. OTANI, H. REUTHER, M. YATSUZUKA, C. M. LEPIENSKI and L. A. BERNI, ibid. 169-170 (2003) 408 .

11. J. E. ZIEGLER, J. P. BIERSACK and U. LITTMARK, "The Stopping and Range of Ions in Solids" (Pergamon, Oxford, 1985).

12. JCPDS (PC-PDF-2), "International Centre for Diffraction Data" (Swarthmor, PA, 1992).

13. H. SCHMIDT, A. SCHMINKE, M. SCHMIEDGEN and B. BARETZK Y, Acta Mater. 49 (2001) 487.

14. Y. ITOH, A. ITOH, H. AZUMA and T. HIOKI, Surf. Coat. Technol. 111 (1999) 172.

15. H. PELletier, D. MUller, P. Mille, A. CORNET and J. J. GROB, ibid. 151-152 (2002) 42.

16. M. A. ARENAS, T. J. TATE, A. CONDE and J. DE DAMB ORENEA, Br. Corros. J. 35 (2000) 232.

17. O. CHEOL and D. K. CHOO, S. LEE, Surf. Coat. Technol. 127 (2000) 76 .

18. I. NAKAMURA, K. MATSUI, M. SASAKI, I. IAKANO and Y. S AWA DA, Vaccum 74 (2004) 659.

19. A. W. EBERHARDT, R. PANDEY, J. M. Williams, J. J. WEIMER, D. IIA and R. L. ZIMMERMAN, Mater. Sci.Eng. A229 (1997) 147.

Received 4 December 2004

and accepted 7 July 2005 